Research Article

\title{
Preparation and Property Study of Organosilicon Antisticking Coatings
}

\author{
Yongfu Zhu $\mathbb{D}^{1},{ }^{1}$ Bojun Cao, ${ }^{1}$ Jitang Zhang, ${ }^{2}$ Xiaojie Zhai, ${ }^{1}$ and Dongbo Guan ${ }^{1}$ \\ ${ }^{1}$ College of Materials Science and Engineering, Key Laboratory of Automotive Materials, Ministry of Education, Jilin University, \\ Changchun 130025, China \\ ${ }^{2}$ Changchun Faway Adient Automotive System Co., Ltd., Changchun 130025, China
}

Correspondence should be addressed to Dongbo Guan; guandb@jlu.edu.cn

Received 12 November 2019; Accepted 31 December 2019; Published 22 January 2020

Academic Editor: Veronica Calado

Copyright (C) 2020 Yongfu Zhu et al. This is an open access article distributed under the Creative Commons Attribution License, which permits unrestricted use, distribution, and reproduction in any medium, provided the original work is properly cited.

In this article, an organosilicon antisticking coating was synthesized from vinyl silicone oil, hydrogen-containing silicone oil, and platinum catalyst. Firstly, the methyl vinyl MQ (mono and quad) silicone resin was added. When the silicone content was 30 wt.\%, the shore hardness and tensile strength increased to about $27.4 \%$ and $115.9 \%$, respectively. Furthermore, nano-SiO $\mathrm{S}_{2}$ powder was added to further improve its antisticking property. This was due to the change of the surface roughness, which could greatly improve the antisticking performance. When the nano- $\mathrm{SiO}_{2}$ powder content was $2 \mathrm{wt} . \%$, the surface free energy and antisticking force were the lowest and the antisticking effect was the best as well and the mechanical properties of silicone rubber had been improved.

\section{Introduction}

Organosilicon materials belong to a kind of chemical compounds containing $\mathrm{Si}-\mathrm{C}$ bonds and have more than one organic group connected with a silicon atom. It includes four major categories: silicone oil, silicone rubber, silicone resin, and silane coupling agent. Silicone rubber is used in exterior materials because its main chain is composed of $\mathrm{Si}-\mathrm{O}-\mathrm{Si}$ bonds, which means it has good thermal oxidation stability, weather resistance, and electrical properties. The hydrophobic nature of silicone rubber surface resists the pollutants and droplets to adhere on its surface, so it can be used as an antisticking coating [1-8]. Therefore, silicone rubber has a wide range of applications in national defense, industry, construction, health care, and daily life. However, its mechanical properties such as tensile strength, hardness, and tear strength are poor and cannot meet the requirements of process production.

MQ silicone resin is a kind of polysiloxane resin, which is composed of monofunctional chain and tetrafunctional chain, wherein the monofunctional chain is $\mathrm{R}_{3} \mathrm{SiO}_{1 / 2}(\mathrm{M})$ and the tetrafunctional chain is $\mathrm{SiO}_{2}(\mathrm{Q})$ [9-13]. As shown in
Figure 1, when two of the $\mathrm{R}$ groups are substituted by a vinyl group and the other $\mathrm{R}$ group is substituted by a methyl group, it is called methyl vinyl MQ silicone resin. Methyl vinyl MQ silicone resins form a type of silicone resin with a core-shell double-layered spherical structure by hydrolytic condensation. Its inner core contains cage-like silica dioxide, and the spherical shell contains an organic group (vinyl). The properties of vinyl MQ silicone resin are between ordinary inorganic polymer compounds and organic polymer compounds, and it has the properties of thermal resistance $[14,15]$, hydrophobicity $[16,17]$, and antisticking. Compared with traditional reinforcing fillers, such as carbon black and silica [18-20], it has the reinforcing function of remarkably improving the mechanical strength of silicone rubber, because of its fine compatibility and mutual solubility. Recently, much attention has been paid to employing composite fillers to improve antisticking performance of polymer composites [21-23]. Based on the addition of the reinforcing agent methyl vinyl MQ resin, the research added the nano- $\mathrm{SiO}_{2}$ powder for further modification [24]. The extra nano- $\mathrm{SiO}_{2}$ powder can lead to physical adsorption, physical entanglements, and so on which can greatly 


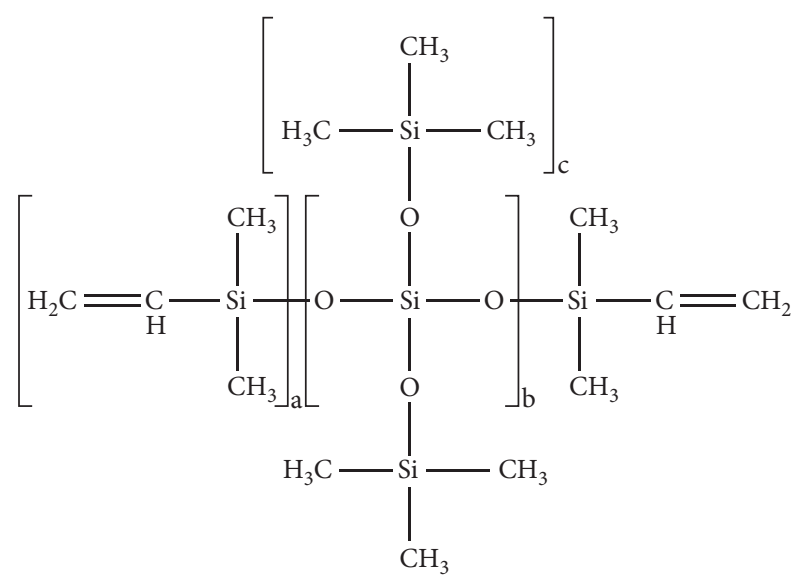

FIGURE 1: Structure of methyl vinyl MQ silicone resin.

increase the degree of crosslinking of the silicone rubber and the tensile strength of the silicone rubber. In addition, nano$\mathrm{SiO}_{2}$ powder can be finely dispersed in silicone rubber.

In this work, different contents of methyl vinyl MQ resin were incorporated into the silicone-based matrix to prepare hybrids. And then, we studied the effect of methyl vinyl MQ resin on the shore hardness, tensile strength, and rheological properties. Thereafter, we studied the effect of nano- $\mathrm{SiO}_{2}$ on the morphology, surface free energy, and antisticking properties of the resulting hybrid coatings.

\section{Materials and Methods}

2.1. Materials. Vinyl silicone oil (viscosity: $300 \mathrm{cp} ; 25^{\circ} \mathrm{C}$, component A) and hydrogen silicone oil (viscosity: $114 \mathrm{cp}$; $25^{\circ} \mathrm{C}$, component B) were purchased from Dongguan Hongfeng Silicone Material Co., Ltd. (China). Pt catalyst (component C) was obtained from Dongguan Hongfeng Silicone Material Co., Ltd. (China), and methyl vinyl MQ silicone resin (viscosity: $11165 \mathrm{cp} ; 25^{\circ} \mathrm{C}$ ) was provided by Shandong Da Yi Chemical Co., Ltd (China). Hydrophobic nano- $\mathrm{SiO}_{2}$ powder (AEROSIL R202, average particle size: $14 \mathrm{~nm}$, specific surface area of $100 \pm 20 \mathrm{~m}^{2} \cdot \mathrm{g}^{-1}$ ) was purchased from EVONIK-DEGUSSA.

2.2. Preparation Process of Silicone Rubber Coating. Al molds are widely used in modern industrial production, so $\mathrm{Al}$ sheets are selected as the base for coatings. The entire preparation process for preparing the silicone coating is shown in Figure 2. First, the Al film was put into an ultrasonic cleaning machine, was cleaned with acetone and ethanol, and was dried. Then, the reaction solution containing vinyl silicone oil, hydrogen silicone oil, methyl vinyl MQ silicone resin and Pt catalyst were poured into the beaker according to the proportion given in Table 1 (Figure 2(c)). After mixing, the hybrid material was poured into the high-pressure nozzle and sprayed to the surface of the Al sheet (Figure 2(d)). Finally, it was dried at $80^{\circ} \mathrm{C}$ for $7 \sim 8 \mathrm{~min}$. The reason why we add methyl vinyl MQ silicone resin was that the hydrogen silicon oil and vinyl silicone oil in the raw material produce a hydrogenated reaction. The molecular structure of methyl vinyl MQ silicone resin contained vinyl bonds, which can react with $\mathrm{Si}-\mathrm{H}$ bond of silicone oil. The reaction process is shown in Figure 3. Vinyl silicone oil, hydrogen silicone oil, and methyl vinyl MQ silicone resin were added to produce silicone coating under the action of platinum catalyst. Therefore, the mechanical properties of the coatings will be improved. In addition, methyl groups will distribute on the surface of the coatings after curing. So it can improve the antisticking performance of the coating surface.

\subsection{Measurement and Techniques}

2.3.1. Fourier Transform Infrared Spectroscopy (FT-IR). The infrared measurements were carried out on a Bruker's TENSOR-27 FT-IR spectrometer at room temperature $\left(25^{\circ} \mathrm{C}\right)$. The infrared spectra of all samples were measured with Attenuated Total Reflection (ATR) accessories. In all cases, 128 scans at a resolution of $4 \mathrm{~cm}^{-1}$ were used to record the spectra.

2.3.2. Contact Angle Measurement. The static contact angle (CA) was carried out on a droplet shape analyzer (DSA10MK2, KRUSS, Germany) at room temperature $\left(25^{\circ} \mathrm{C}\right)$. The contact angles on the surfaces of all the specimens were measured with 5-8 $\mu \mathrm{l}$ of water and ethylene glycol. Each of the reported CAs represents the average value of five measurements.

2.3.3. Scanning Electron Microscopy (SEM). Surface morphology was analyzed by scanning electron microscopy (ZEISSEVO18) with an acceleration voltage of $30 \mathrm{kV}$ at room temperature $\left(25^{\circ} \mathrm{C}\right)$.

2.3.4. Atomic Force Microscopy (AFM). Surface roughness analysis was carried out on an atomic force microscope (FMNanoview 1000, China). Each of the reported surface roughness values represented the average value of five measurements.

2.3.5. Rotational Rheometer. The rheological properties were tested on a rotary rheometer (ARES-G2 type of TA Company, USA). A $25 \mathrm{~mm}$ parallel plate clamp was used, and the frequency was set to $10 \mathrm{rad} / \mathrm{s}$. Scanning strain and frequency range of oscillation frequency were set at $1 \%$ and $0.1-500 \mathrm{rad} / \mathrm{s}$, respectively. The steady-state shear frequency ranged from $10^{-3}$ to $10^{3} \mathrm{~s}^{-1}$, the time scanning frequency was $1 \%$, and the strain was $1 \%$.

\section{Results and Discussion}

The shore hardness value of the samples increased when the content of MQ silicone resin increased from $0 \mathrm{wt} \%$ to 30 wt.\% as shown in Figure 4(a). However, further addition of MQ silicone resin leads a bit slope of shore hardness. The tensile strength can reach $175.0 \mathrm{kPa}$ when the content of MQ was 5 wt.\%. More MQ to 10 wt.\% was added, and the tensile 


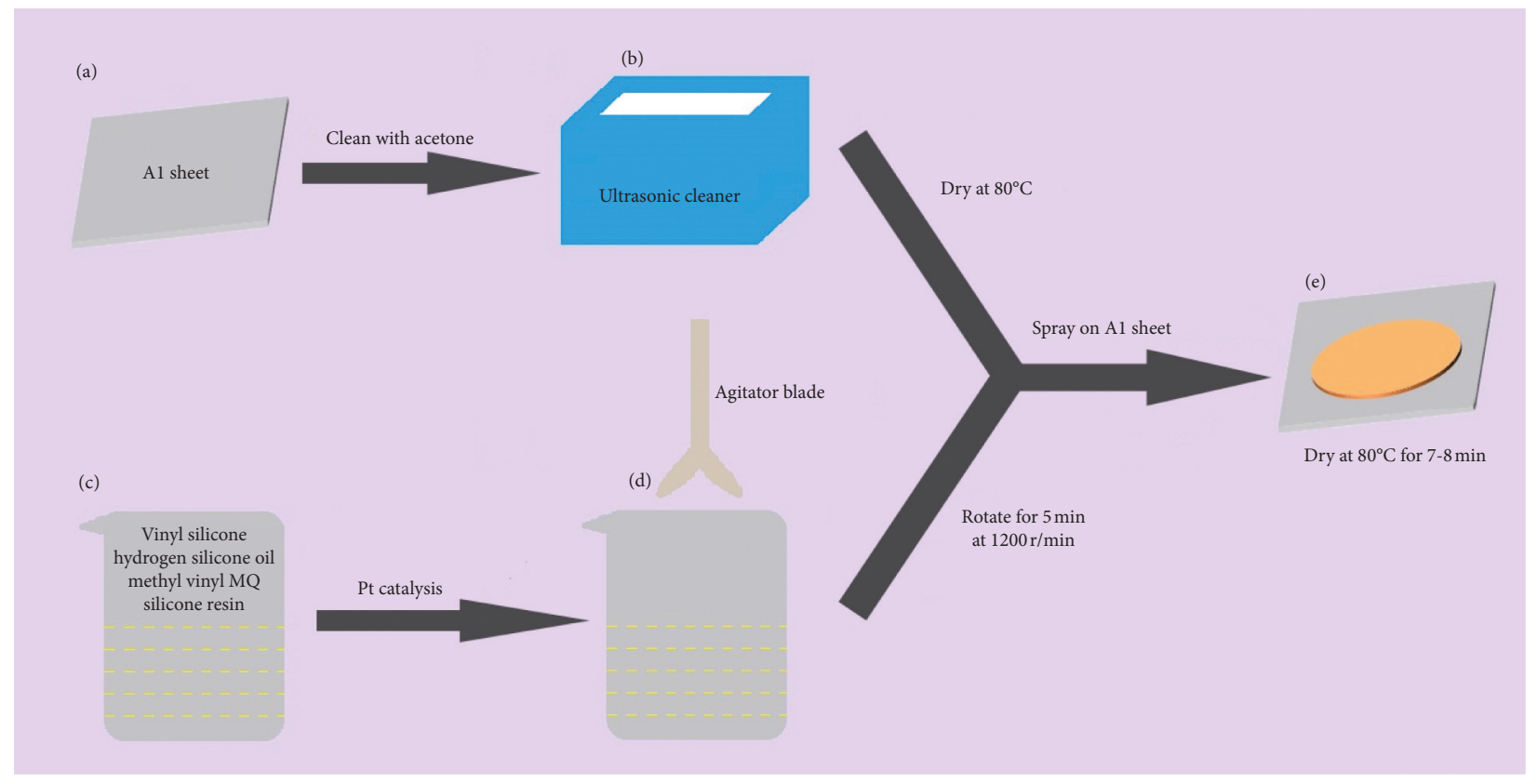

FIgURE 2: Preparation process of antisticking silicone rubber: $(\mathrm{a}, \mathrm{b})$ the cleaning and drying process for the $\mathrm{Al}$ sheet, (c, d) mixing of components, and (e) the curing process of coating sprayed on $\mathrm{Al}$ sheet.

TABLE 1: Mass ratio of methyl vinyl MQ silicone resin samples.

\begin{tabular}{lcccc}
\hline Samples no. & Vinyl silicone oil $(\mathrm{g})$ & Hydrogen containing silicone oil $(\mathrm{g})$ & Pt catalyst $(\mathrm{g})$ & Methyl vinyl MQ silicone resin $(\mathrm{g})$ \\
\hline 1 & 5.00 & 0.175 & 0.04 & 0.00 \\
2 & 4.75 & 0.175 & 0.04 & 0.25 \\
3 & 4.50 & 0.175 & 0.04 & 0.50 \\
4 & 4.00 & 0.175 & 0.04 & 1.00 \\
5 & 3.50 & 0.175 & 0.04 & 1.50 \\
6 & 2.50 & 0.175 & 0.04 & 2.50 \\
\hline
\end{tabular}

The mass percentage of methyl vinyl MQ silicone resin is based on the total mass of methyl vinyl MQ silicone resin and vinyl silicone oil.

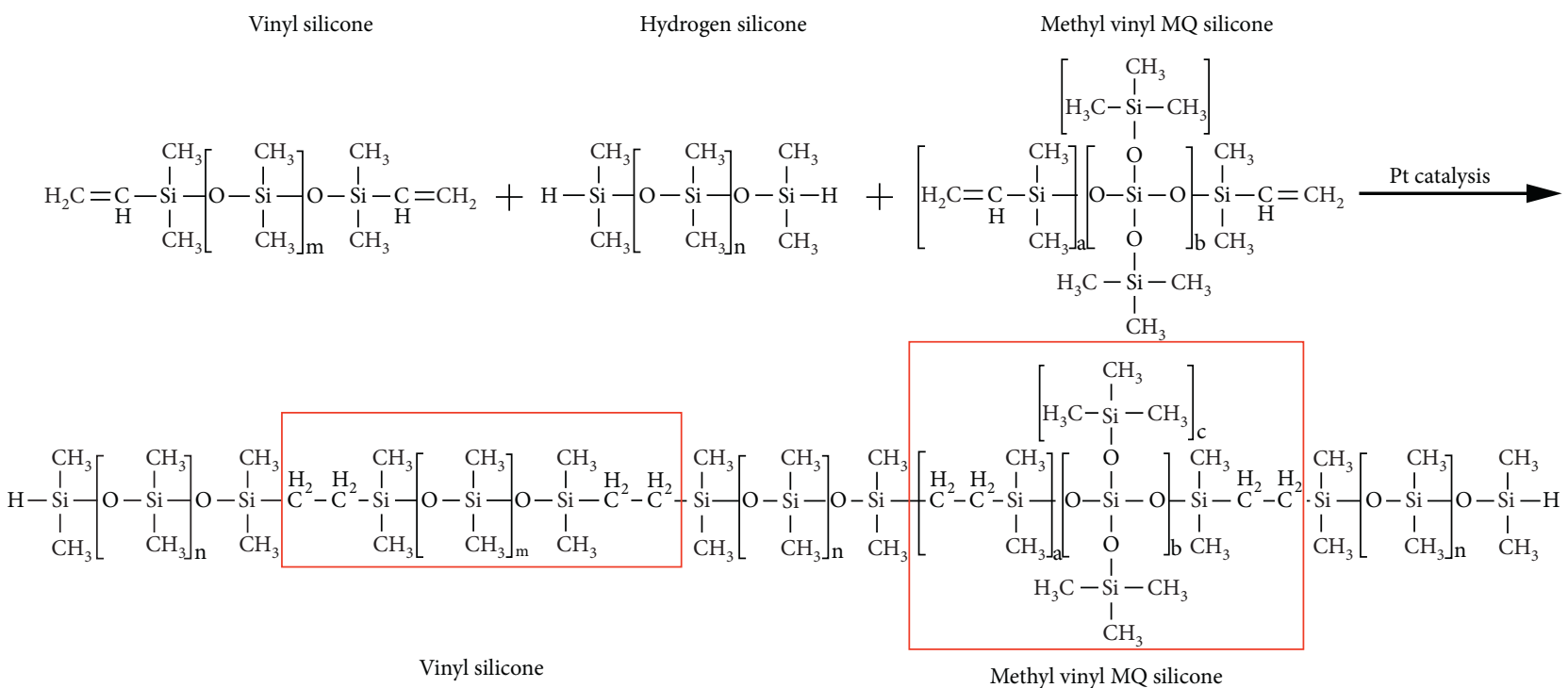

FIGURE 3: Reaction of the process of coating preparation.

strength decreased to $165.2 \mathrm{kPa}$, because the hydroxyl in the reactant reacted with the water vapor in the air to generate hydrogen. In Figure 4(b), when MQ was not added, the tensile strength was $104.7 \mathrm{kPa}$. However, when the content of MQ reached $30 \mathrm{wt} . \%$, the tensile strength of MQ was $226.6 \mathrm{kPa}$, increasing by $115.9 \%$. Therefore, when the 


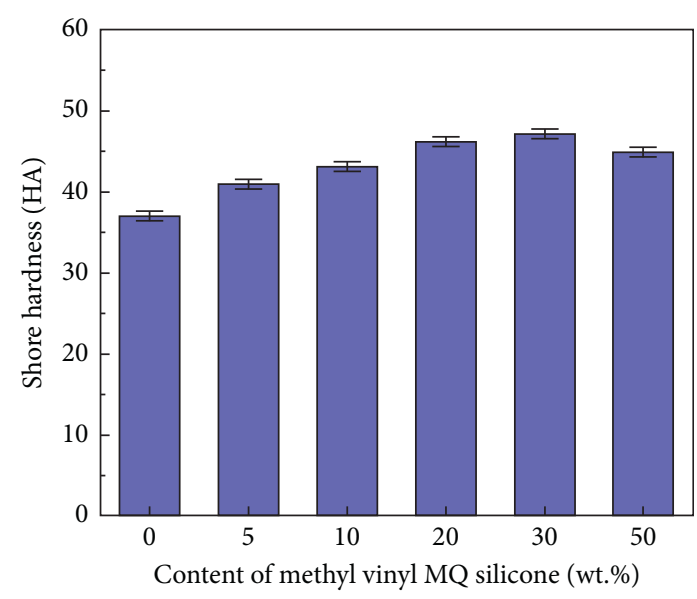

(a)

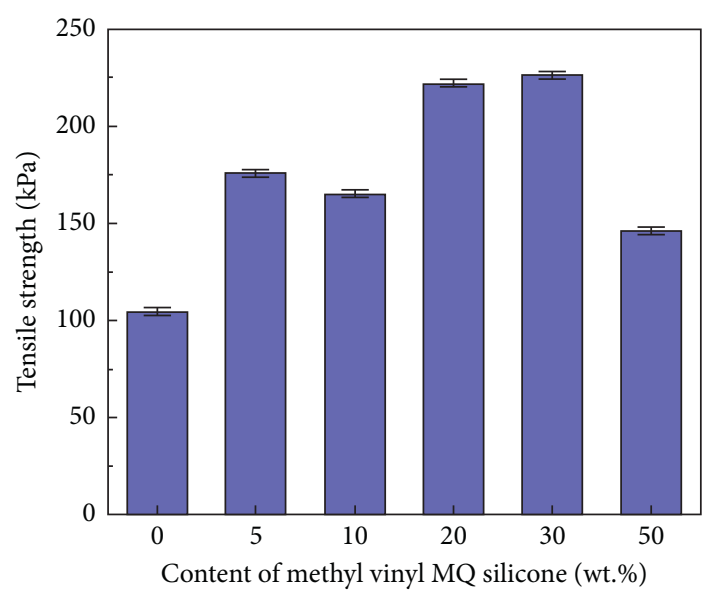

(b)

FIgURE 4: (a) Shore hardness and (b) tensile strength with different contents of methyl vinyl MQ silicone.

content of methyl vinyl MQ silicone resin was $30 \mathrm{wt} . \%$, the mechanical modification effect of silicone rubber was the most significant.

The reaction temperature and time have been the two key factors affecting the chemical reaction, among which the reaction temperature has significant influence on the $t_{\text {gel }}$ (gelation time). In general, the higher the reaction temperature, the shorter the $t_{\text {gel }}$. To explain the rationality of curing silicone coatings at $80^{\circ} \mathrm{C}$, the rheological tests of samples with MQ content of $30 \mathrm{Wt}$.\% were carried out. At the different temperatures, the $G^{\prime}$ and $G^{\prime \prime}$ changed with the reaction time as shown in Figure 5(a). At the initial stage of the reaction, $G^{\prime}$ and $G^{\prime \prime}$ slowly increased with time. As the reaction increased rapidly and $G^{\prime}$ was greater than $G^{\prime \prime}$. Finally, $G^{\prime \prime}$ increased slowly and tended to smooth. At the beginning of the reaction, $G^{\prime \prime}$ was greater than $G^{\prime}$ and the material was mainly in sticky state, so it was liquid. With the progress of the reaction, at a certain time $G^{\prime \prime}=\mathrm{G}^{\prime}$, and the $t_{\text {gel }}$ appeared. This point was a special dispersion system, which was a spatial network structure formed by colloidal particles or polymers in solution or sol connected under certain conditions. After a period of time, $G^{\prime \prime}$ was less than $G^{\prime}$, and the material was mainly in elastic deformation state, so the material becomes solid. It can be seen that the $t_{\text {gel }}$ gradually decreased with the increase of temperature, and the curve was parabolic as shown in Figure 5(b). We would also like to measure the $t_{\mathrm{gel}}$ at $100^{\circ} \mathrm{C}$, but the time was very close to the loading time of the rheometer. Therefore, the $t_{\text {gel }}$ at $100^{\circ} \mathrm{C}$ was obtained by theoretical deduction. The total activation energy of crosslinking reaction can be obtained from the $t_{\text {gel }}$. It was assumed that the curing reaction can be described by using a differential equation, which included an apparent activation energy, as follows [25]:

$$
\frac{\mathrm{d} \alpha}{\mathrm{d} t}=A \exp \left(-\frac{E}{R T}\right) f(\alpha)
$$

In the formula: $\alpha$ is the degree of reaction, $A$ is a coefficient, $E$ is the apparent activation energy of the total reaction, $R$ is a gas constant, $T$ is the isothermal curing temperature, and $f(\alpha)$ is a function of $\alpha$ and has nothing to do with the curing temperature.

According to Flory's gelation theory [25], the reaction degree at a gelation point should remain constant at different reaction temperatures. From $\alpha=0$ to $\alpha=\alpha_{\text {gel }}$, the following formula was obtained for the equation integration $[25,26]$ :

$$
\ln \int_{0}^{\alpha_{\mathrm{gel}}} \frac{d \alpha}{f(\alpha)}=\ln A+\ln t_{\mathrm{gel}}+\left(-\frac{E}{R T}\right) .
$$

The left side of the equation was independent of the reaction temperature, so there was

$$
\ln t_{\text {gel }}=C+\frac{E}{R T} \text {. }
$$

From this equation, we can see that $\ln t_{\text {gel }}$ was proportional to $1 / \mathrm{T}$. The relationship between the $t_{\text {gel }}$ and temperature at 40,60 , and $80^{\circ} \mathrm{C}$ was converted into Figure $5(\mathrm{c})$. The relation of the diagram approximated a straight line, which indirectly illustrated the accuracy of the experimental data. Through the expansion of the equation, we can get that $t_{\text {gel }}$ was $37 \mathrm{~s}$ at $373 \mathrm{k}$. These data were combined with previous experimental data (Figure 5(b)) to obtain Figure 5(d). It can be seen from Figure $5(\mathrm{~d})$ that with the increase of temperature, the rate of the $t_{\text {gel }}$ dropped slowly. In the process of increasing from $80^{\circ} \mathrm{C}$ to $100^{\circ} \mathrm{C}$, $t_{\text {gel }}$ only reduced by about $40 \mathrm{~s}$, but the energy of heating loss was greater. So the optimize curing temperature was $80^{\circ} \mathrm{C}$.

In the results of previous shore hardness and tensile tests, it was found that the silicone rubber containing $30 \mathrm{wt} . \%$ methyl vinyl MQ silicone resin has the best performance. So on this basis, we tried to add $1 \mathrm{wt} . \%, 2 \mathrm{wt} \%$, $3 \mathrm{wt} . \%$, and 4 wt. $\%$ nano- $\mathrm{SiO}_{2}$ powder for one step modification and improvement.

In order to understand the reaction degree of each reactant, infrared spectral measurement was carried out. As can be seen from Figure 6, the strong absorption peak at $2960 \mathrm{~cm}^{-1}$ was the stretching vibration absorption peak of $\mathrm{C}-\mathrm{H}$ in $\mathrm{CH}_{3}$, and the more obvious absorption peak appears at 1257,864 , and $785 \mathrm{~cm}^{-1}$, which was the extension of 


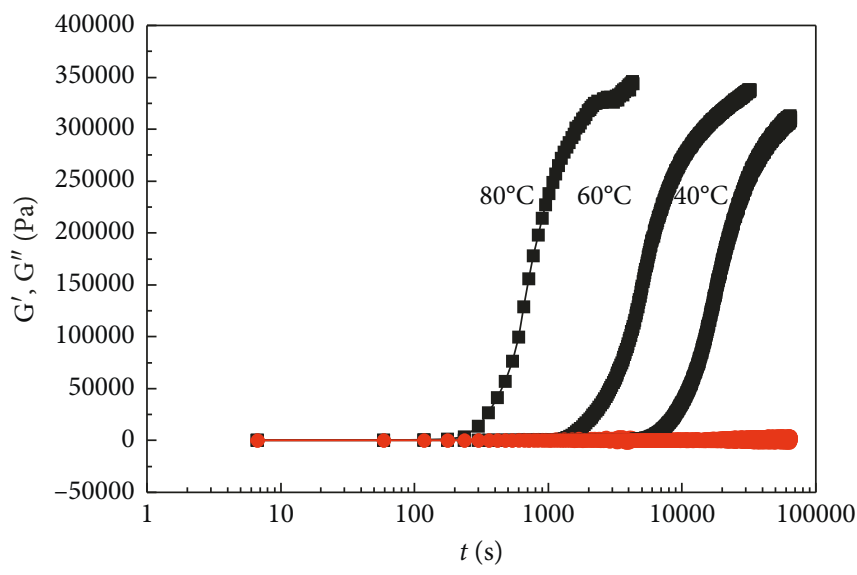

$\rightarrow \mathrm{G}^{\prime}$

- $\mathrm{G}^{\prime \prime}$

(a)

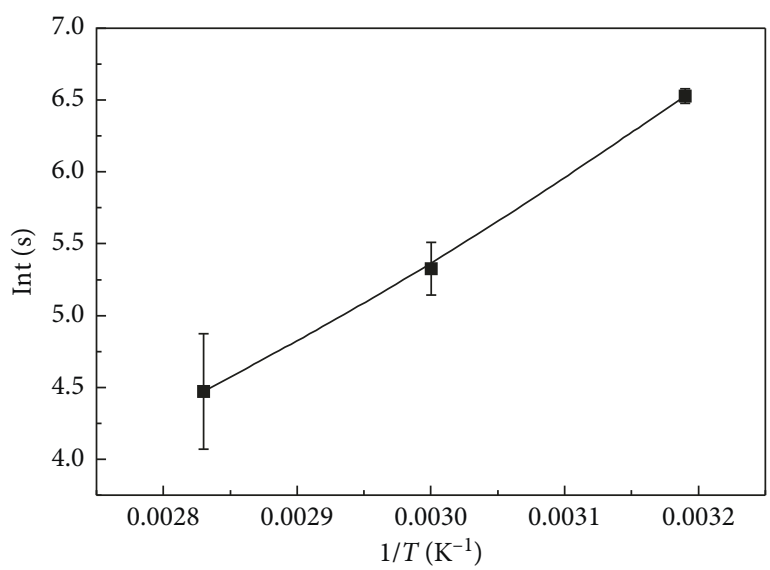

(c)

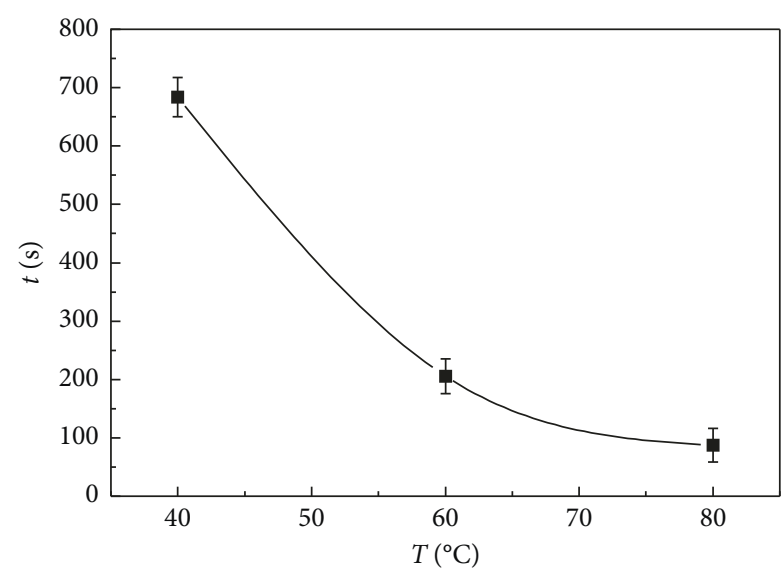

(b)

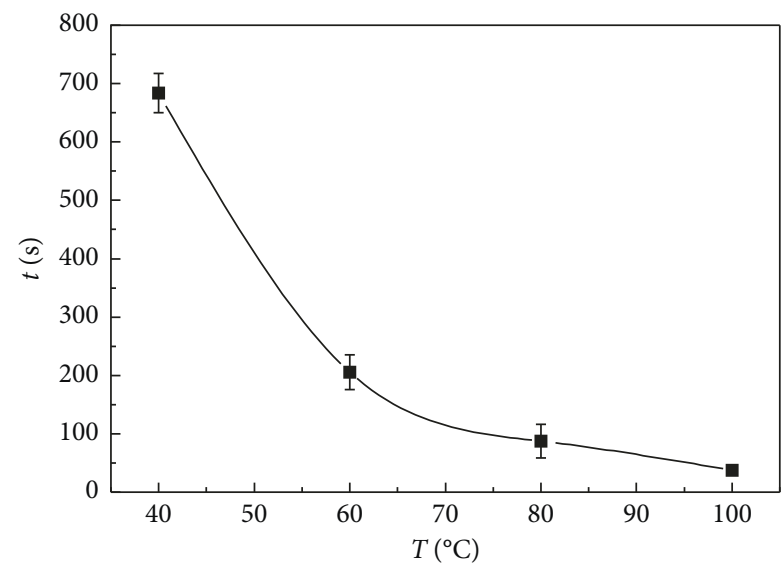

(d)

Figure 5: The data diagrams of rheological tests: (a) storage modulus $\left(\mathrm{G}^{\prime}\right)$ and loss modulus $\left(\mathrm{G}^{\prime \prime}\right)$ over time at 40,60 , and $80^{\circ} \mathrm{C}$, (b) gelation time at each temperature, (c) the relationship curve obtained from Flory's gel theory, and (d) the relationship between experimental and theoretical gelation time and temperature.

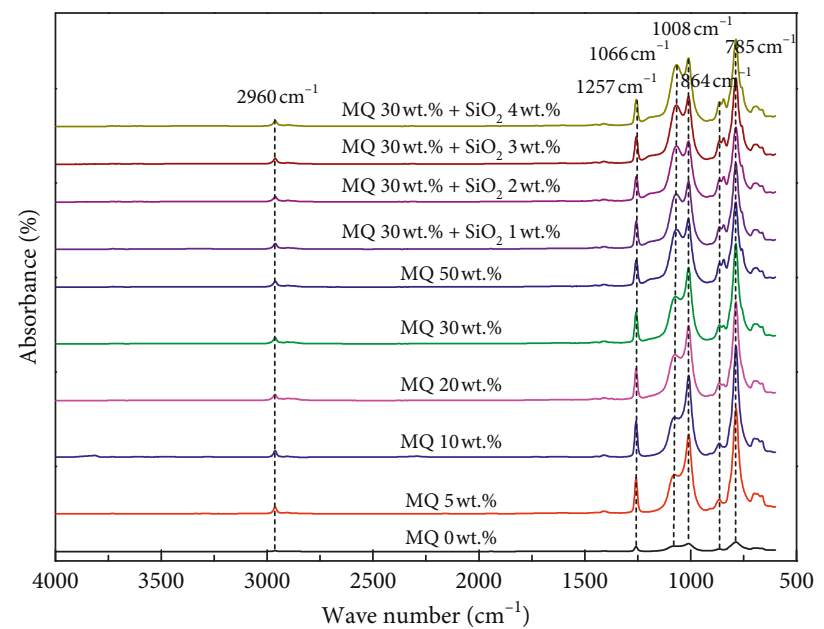

FIGURE 6: FT-IR spectra of coatings with different contents of methyl vinyl MQ silicone and nano-SiO ${ }_{2}$ powder. 
silicon methyl $\left(\mathrm{Si}-\mathrm{CH}_{3}\right)$ vibration peak. A broad and strong double-peak absorption peak appeared within $1000-1100 \mathrm{~cm}^{-1}$, which was the stretching vibration absorption peak of $\mathrm{Si}-\mathrm{O}-\mathrm{Si}$. There was almost no absorption peak at $3500-3700 \mathrm{~cm}^{-1}$, indicating that almost no hydroxyl groups were present, which results in a decrease in the hydrophilicity of the silicon coating.

In order to know the relationship between surface morphology and surface free energy, the surface morphology of the coating was observed by using SEM, the roughness indicated by the coating was obtained by AFM, and the surface free energy was obtained by the contact angle.

The average value of the contact angle was used to calculate the surface free energy. The calculation method was as follows:

According to the Young equation,

$$
\begin{aligned}
\gamma_{\mathrm{LV}}(1+\cos \theta) & =2 \sqrt{\gamma_{\mathrm{SV}}^{\mathrm{d}} \gamma_{\mathrm{LV}}^{\mathrm{d}}}+2 \sqrt{\gamma_{\mathrm{SV}}^{\mathrm{p}} \gamma_{\mathrm{LV}}^{\mathrm{p}}}, \\
\gamma_{\mathrm{SV}} & =\gamma_{\mathrm{SV}}^{\mathrm{p}}+\gamma_{\mathrm{SV}}^{\mathrm{d}}
\end{aligned}
$$

where $\gamma_{\mathrm{SV}}$ and $\gamma_{\mathrm{LV}}$ are the surface free energy of solid and liquid, $\gamma_{S V}^{\mathrm{P}}$ and $\gamma_{\mathrm{LV}}^{\mathrm{P}}$ are the polar parts of the surface free energy of solid and liquid, and $\gamma_{\mathrm{SV}}^{\mathrm{d}}$ and $\gamma_{\mathrm{LV}}^{\mathrm{d}}$ are the dispersive parts of the surface free energy of solid and liquid.

As can be seen from Figure 7(a), the surface of sample was very smooth, which has no phenomenon of convexconcave structures. It can be seen that there are some white block-like raised substances from its surface in Figure $7(\mathrm{~b})$, which may be caused by the agglomeration of $\mathrm{SiO}_{2}$ inside the silicone rubber and made some convex and concave structures appear on its surface. In Figure $7(\mathrm{c})$, we could clearly see the existence of some white highlights, which may be due to the transfer of $\mathrm{SiO}_{2}$ from inside to outside, making the surface more rough. From the surface morphology of the sample shown in Figures $7(\mathrm{~d})$ and $7(\mathrm{e})$, it could be clearly seen that the distribution of convex and concave structures on the coating surface tends to be uniform. Roughness begins to decrease.

The change of coating surface roughness also brought about the change of contact angle between glycol and deionized water. With the increase of the content of nano$\mathrm{SiO}_{2}$ powder, the contact angle of ethylene glycol tended to rise first and then decreased. The contact angle of ethylene glycol will increase with the increase of surface roughness, so its change tendency was the same as that of roughness. However, the trend of the contact angle of deionized water was slightly different. It was mainly at the stage where the content of nano- $\mathrm{SiO}_{2}$ powder increased from $1 \mathrm{wt} . \%$ to $2 \mathrm{wt} . \%$. This may be due to the large agglomeration of nano$\mathrm{SiO}_{2}$ powder, which causes the surface roughness to be too large, which causes the contact angle not only to increase but to decrease. This may be due to a large number of agglomerations of nano- $\mathrm{SiO}_{2}$ powder, resulting in excessive surface roughness, which made the contact angle not increase but decrease.
In order to further study the effect of surface roughness on surface antisticking properties, we used the probe scanning method on the surface of the sample to observe the 3D morphology of the silicone rubber surface. As can be seen from Figures 8(a)-8(c), within a certain range, the number of convex and concave structures on the coating surface increases gradually. When the content of $\mathrm{SiO}_{2}$ is $2 \mathrm{wt}$. \%, the distribution of convex and concave structures is more uniform and the surface roughness is larger. When the content of $\mathrm{SiO}_{2}$ was less than $2 \mathrm{wt} . \%$, the surface roughness gradually increased. When the content of $\mathrm{SiO}_{2}$ was larger than $2 \mathrm{wt} . \%$, the surface roughness decreased. With the increase of $\mathrm{SiO}_{2}$ content, the number of dispersed aggregated powders on the coating surface decreases, which led to the decrease of surface roughness to a certain extent.

From Figure 9, it can be seen that the change of surface free energy was completely opposite to that of surface roughness, showing a trend of decreasing first and then increasing. When the content of $\mathrm{SiO}_{2}$ was less than $2 \mathrm{wt} . \%$, the surface free energy decreased gradually. When the content of $\mathrm{SiO}_{2}$ was $2 \mathrm{wt} . \%$, the contact angle of ethylene glycol and deionized water on the coating surface was not very large, but it had the lowest surface free energy. Low surface energy is the best manifestation of excellent antiadhesion performance, and the value of contact angle can only reflect the affinity for a single liquid. When the content of $\mathrm{SiO}_{2}$ was more than $2 \mathrm{wt} . \%$, the surface free energy increases gradually, but with the increase of the content, the increasing speed slowed down.

In order to study more intuitively the antisticking property of the coating surface, we had also carried out a more direct and obvious test method for antisticking performance which was called the peeling force test.

First, the polyurethane foam tape with $3.5 \mathrm{~cm}$ width of $1.8 \mathrm{~cm}$ was intercepted and marked at $2.5 \mathrm{~cm}$. After placing it on the surface of the coating, $750 \mathrm{~g}$ weight was applied to the surface of the tape for 5 minutes. After holding the remaining $1 \mathrm{~cm}$ part of the tape with a tension gauge, it was moved vertically upward, and the value was recorded when the tape is completely stripped from the coating surface.

It can be seen from Figure 10 that the antisticking force was $18 \mathrm{~g} / 25 \mathrm{~mm}$ without nano- $\mathrm{SiO}_{2}$ powder. With the increase of nano- $\mathrm{SiO}_{2}$ power content, the antisticking force decreased first and then increased. When the content of nano$\mathrm{SiO}_{2}$ powder was $2 \mathrm{Wt}$.\%, the minimum antisticking force was $12 \mathrm{~g} / 25 \mathrm{~mm}$. At this time, the antisticking force of the coating was the lowest and the antisticking property was the best.

\section{Conclusions}

In conclusion, we had successfully developed a new antisticking organosilicon coating. Methyl vinyl MQ silicone resin was introduced into the original coating. When methyl vinyl MQ silicone resin content reached $30 \mathrm{wt} . \%$, the mechanical properties of the coating were the best because it reacted with excess $\mathrm{Si}-\mathrm{H}$ bonds in hydrogen silicone oil to form a denser network structure. But its antisticking performance was not ideal. The addition of nano- $\mathrm{SiO}_{2}$ powder would change the 


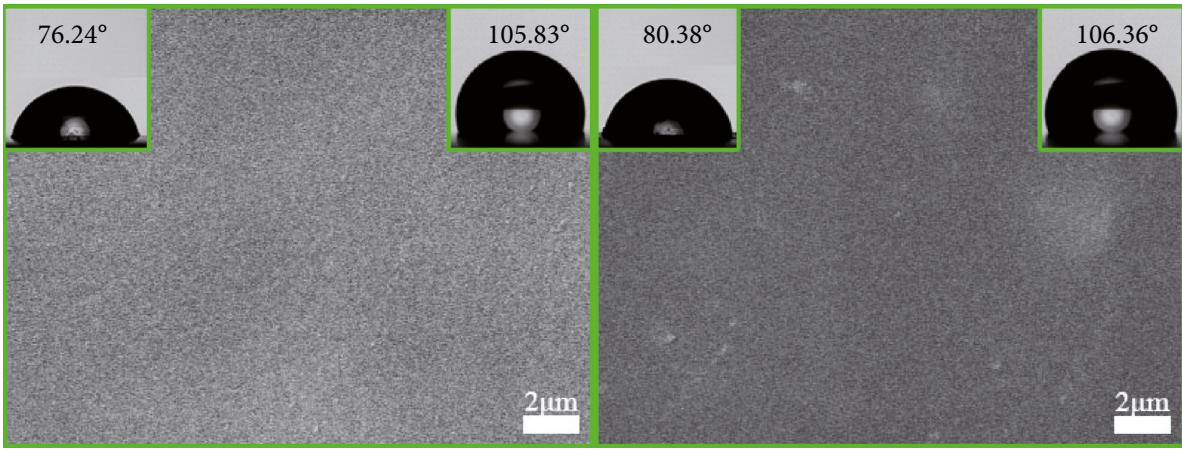

(a)

(b)

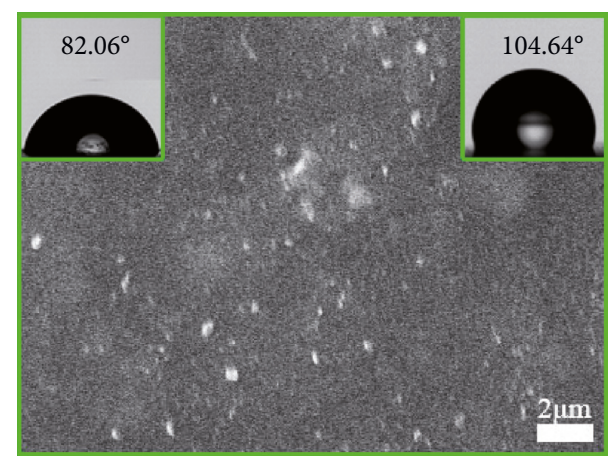

(c)

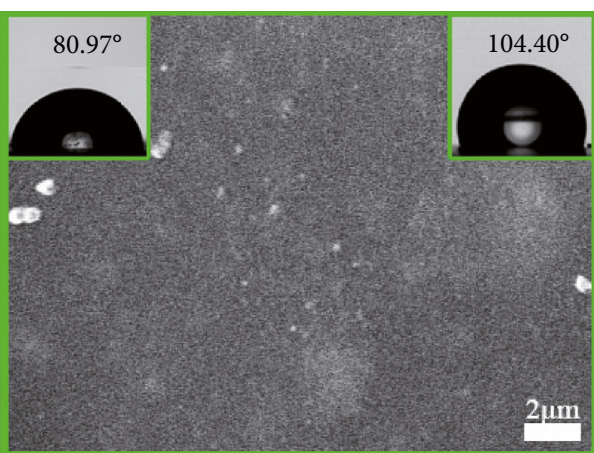

(d)

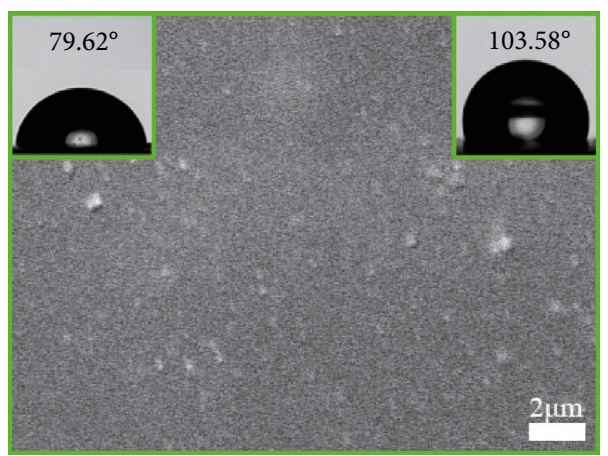

(e)

FIGURE 7: SEM images of organosilicon antisticking coatings. (a) $30 \mathrm{wt} . \%$ methyl vinyl MQ silicone resin. (b-e) Coating with 1 wt.\%, 2 wt.\%, 3 wt.\%, and 4 wt.\% nano- $\mathrm{SiO}_{2}$ powder on the basis of (a), respectively. The contact angles of the left and right labels in each image were separately those of ethylene glycol and deionized water.

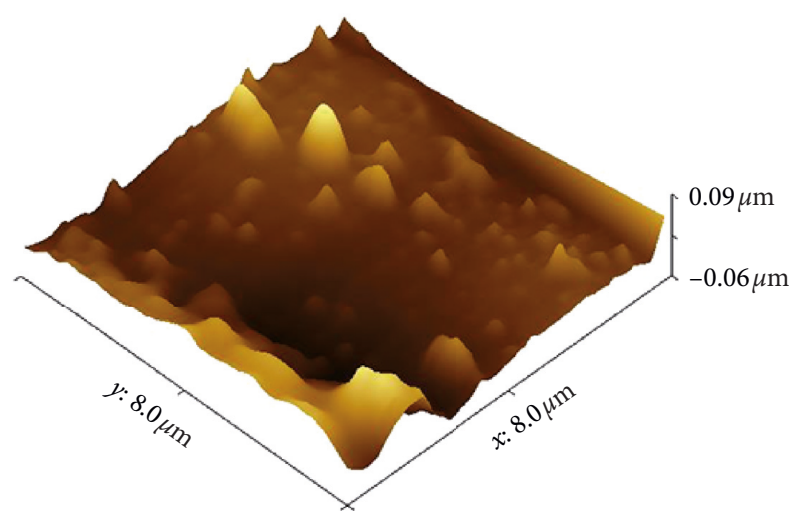

(a)

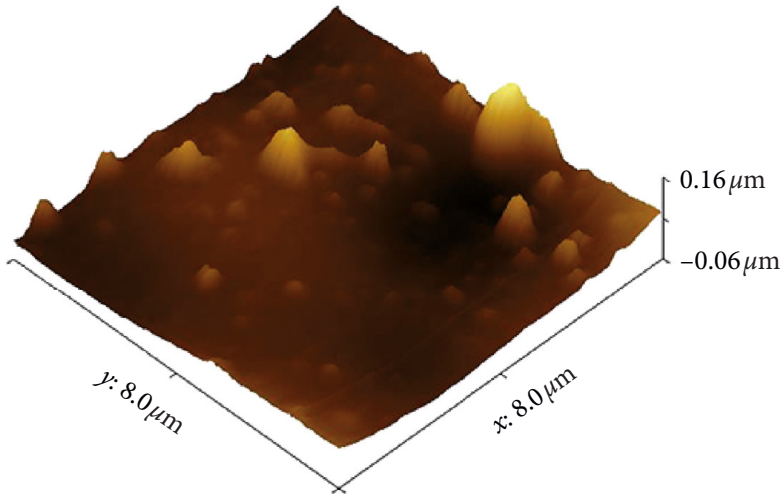

(b)

Figure 8: Continued. 


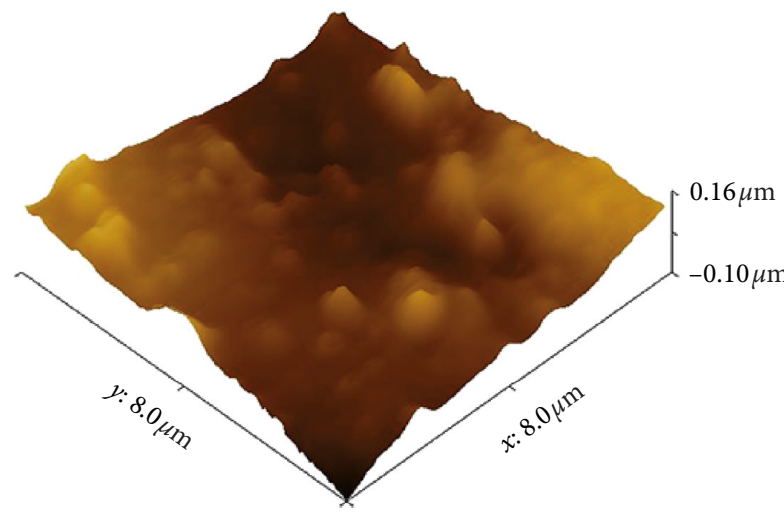

(c)

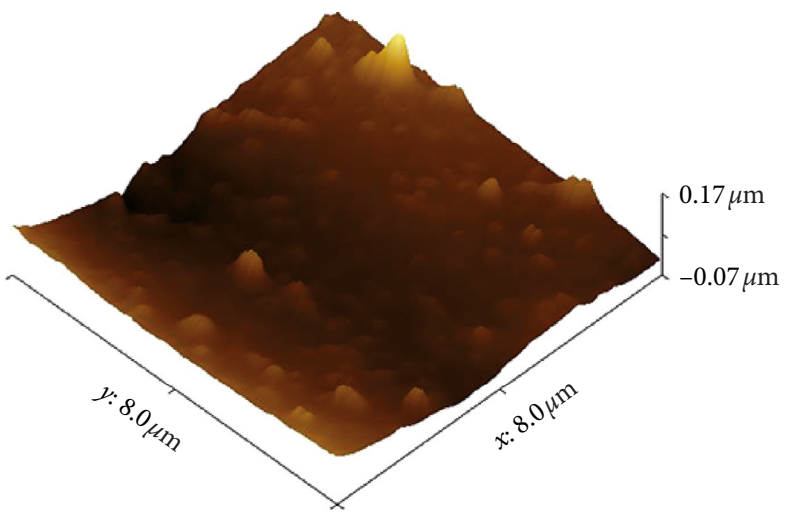

(d)

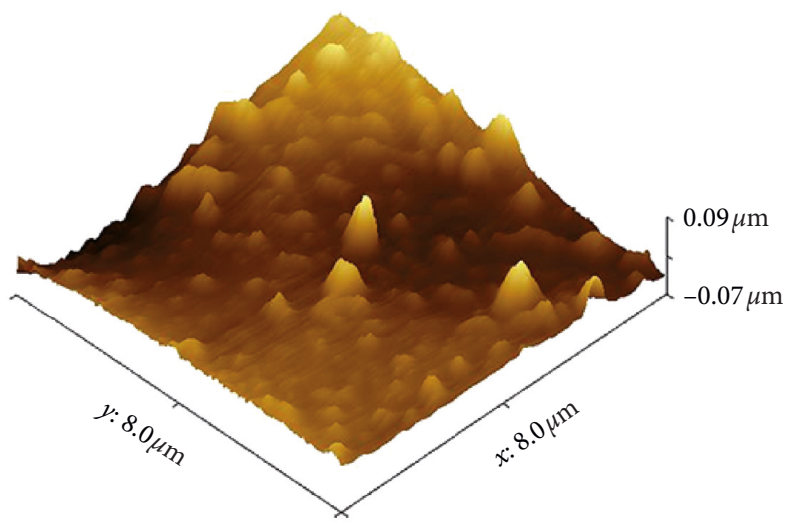

(e)

FIGURE 8: AFM images of organosilicon antisticking coatings. (a) 30 wt.\% methyl vinyl MQ silicone resin. (b-e) Coating with 1 wt.\%, 2 wt.\%, 3 wt.\%, and 4 wt.\% nano- $\mathrm{SiO}_{2}$ powder on the basis of (a), respectively.

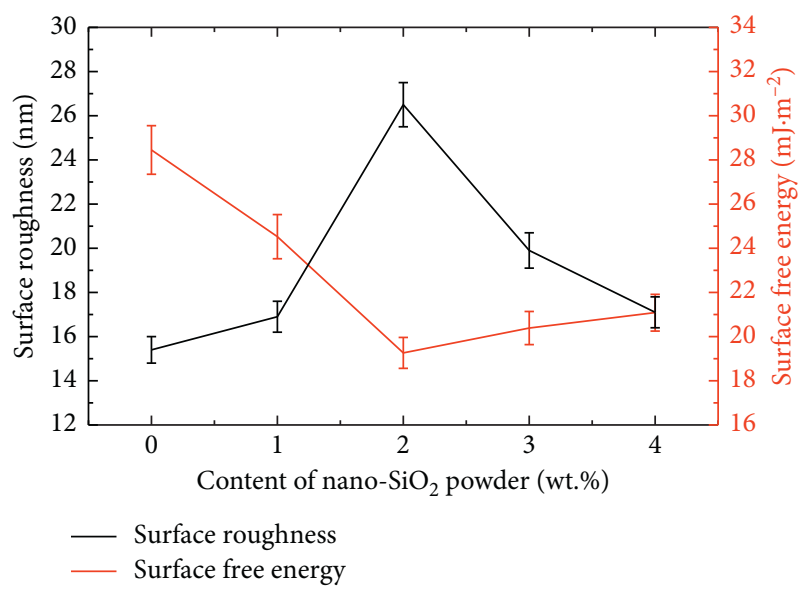

FIGURE 9: Surface roughness and surface free energy of silicone antisticking coatings.

surface roughness of the coating and improve the antisticking performance of the coating. When the content of nano- $\mathrm{SiO}_{2}$ reached $2 \mathrm{wt} . \%$, the tensile strength and antisticking property of the coating were the best:

(1) Adding nano- $\mathrm{SiO}_{2}$ powder on the basis of MQ $30 \mathrm{wt} . \%$ helped to improve the antisticking performance of the coating.

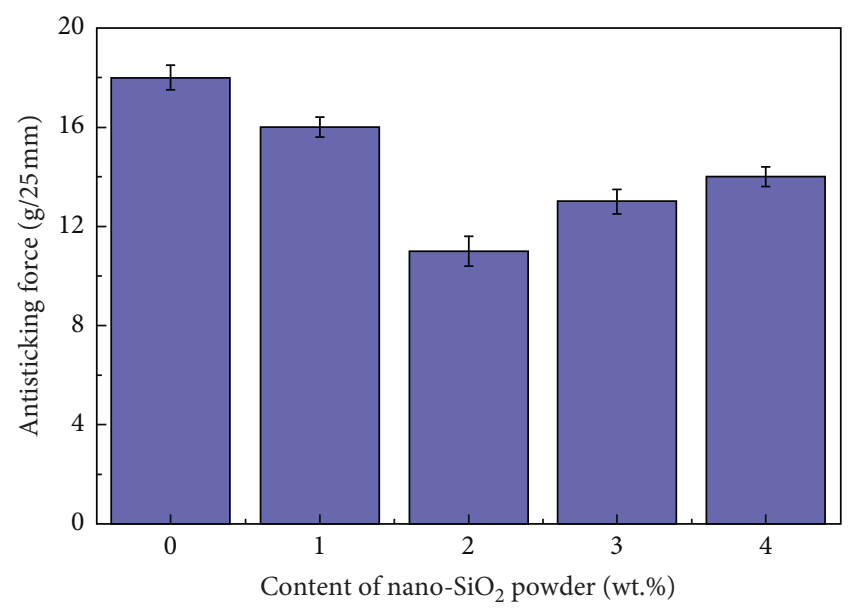

FIgURE 10: Antisticking force with different contents of nano- $\mathrm{SiO}_{2}$ power.

(2) When the nano- $\mathrm{SiO}_{2}$ powder content reached $2 \mathrm{wt} . \%$, the surface free energy was the lowest and the antisticking performance was also the best.

(3) The antisticking performance of the coating surface is mainly determined by its surface roughness and surface free energy. The greater the surface 
roughness, the lower the surface free energy and the better the antisticking property of the coating surface.

\section{Data Availability}

The data supporting the findings of this study are available within the paper and its supplementary information and supplementary data. Extra data are available from the corresponding author upon reasonable request.

\section{Conflicts of Interest}

The authors declare that they have no conflicts of interest.

\section{Acknowledgments}

This work was supported by the Special Project of Industrial Technology Research and Development of Jilin Province (2019C059-6) and the Key Scientific and Technological Research and Development Project of Jilin Province (20180201080GX).

\section{References}

[1] A. Pavesio, D. Renier, C. Cassinelli, and M. Morra, "Antiadhesive surfaces through hyaluronan coatings," Medical Device Technology, vol. 8, no. 7, pp. 24-7, 1997.

[2] J. Wang, Z. Wang, S. Guo et al., "Antibacterial and antiadhesive zeolite coatings on titanium alloy surface," Microporous and Mesoporous Materials, vol. 146, no. 1-3, pp. 216-222, 2011.

[3] E. Velzenberger, M. Vayssade, G. Legeay, and M.-D. Nagel, "Study of cell behaviour on a cellulose anti-adhesive substratum," Cellulose, vol. 15, no. 2, pp. 347-357, 2008.

[4] R. W. Jaszewski, H. Schift, B. Schnyder, A. Schneuwly, and P. Gröning, "The deposition of anti-adhesive ultra-thin teflonlike films and their interaction with polymers during hot embossing," Applied Surface Science, vol. 143, no. 1-4, p. 301, 1999.

[5] G. W. Greene, L. L. Martin, R. F. Tabor, A. Michalczyk, L. M. Ackland, and R. Horn, "Lubricin: a versatile, biological anti-adhesive with properties comparable to polyethylene glycol," Biomaterials, vol. 53, pp. 127-136, 2015.

[6] D. S. Raie, E. Mhatre, M. Thiele et al., "Application of quercetin and its bio-inspired nanoparticles as anti-adhesive agents against Bacillus subtilis attachment to surface," Materials Science and Engineering: C, vol. 70, pp. 753-762, 2016.

[7] X. Liu, L. Peng, J. Meng, Z. Zhu, B. Han, and S. Wang, "Protein-mediated anti-adhesion surface against oral bacteria," Nanoscale, vol. 10, no. 6, pp. 2711-2714, 2018.

[8] J. W. Kim, E. H. Kim, G. D. Han et al., "Preparation of visible light-curable carrageenan derivatives for application as antiadhesion agent," Polymer Korea, vol. 42, no. 5, pp. 400-408, 2018.

[9] Y. Huang, "The effect of the acid catalyst on the preparation of MQ silicone resins," Chinese Journal of Polymer Science Part A: Polymer Chemistry, vol. 17, no. 5, p. 429, 1999.

[10] F. Sun, Y. Hu, and H.-G. Du, "Synthesis and characterization of MQ silicone resins," Journal of Applied Polymer Science, vol. 125, no. 5, pp. 3532-3536, 2012.

[11] K. Yoshii, T. Yamashita, S. Machida et al., "Photo-probe study of siloxane polymers. I. Local free volume of an MQ-type silicone resin containing crosslinked nanoparticles probed by photoisomerization of azobenzene," Journal of Non-Crystalline Solids, vol. 246, no. 1-2, pp. 90-103, 1999.

[12] X. Shi, Z. Chen, and Y. Yang, "Toughening of poly (l-lactide) with methyl MQ silicone resin," European Polymer Journal, vol. 50, no. 1, pp. 243-248, 2014.

[13] D. Z. Chen, F. X. Chen, X. Y. Hu, H. W. Zhang, X. Z. Yin, and Y. S. Zhou, "Thermal stability, mechanical and optical properties of novel addition cured PDMS composites with nano-silica sol and MQ silicone resin," Composites Science and Technology, vol. 117, no. 6, p. 307, 2015.

[14] D. Kumar, K. N. Pandey, and D. K. Das, "Microstructure studies of air-plasma-spray-deposited CoNiCrAlY coatings before and after thermal cyclic loading for high-temperature application," International Journal of Minerals, Metallurgy, and Materials, vol. 23, no. 8, pp. 934-942, 2016.

[15] D. Zhu, F. Luo, L. Xiong, and W. Zhou, "Study on mechanical properties of high-temperature absorbing coats," Materials Letters, vol. 61, no. 8-9, pp. 1760-1762, 2007.

[16] Y. Sugimura, K. Fukunaga, T. Matsuno, K. Nakao, M. Goto, and F. Nakashio, "A study on the surface hydrophobicity of lipases," Biochemical Engineering Journal, vol. 5, no. 2, pp. 123-128, 2000 .

[17] W. Liang and J. J. Cheng, "Improvement of hydrophobicity of phosphate optical glass by a silane surface coating," Glass Technology: European Journal of Glass Science and Technology Part A, vol. 42, no. 1, p. 36, 2001.

[18] J. Zhang, S. Y. Feng, and Q. Y. Ma, "Kinetics of the thermal degradation and thermal stability of conductive silicone rubber filled with conductive carbon black," Journal of Applied Polymer Science, vol. 89, no. 6, p. 1548, 2010.

[19] J. K. Oh, K. Perez, N. Kohli et al., "Hydrophobically-modified silica aerogels: novel food-contact surfaces with bacterial antiadhesion properties," Food Control, vol. 52, pp. 132-141, 2015.

[20] C. Urata, G. J. Dunderdale, M. W. England, and A. Hozumi, "Self-lubricating organogels (SLUGs) with exceptional syneresis-induced anti-sticking properties against viscous emulsions and ices," Journal of Materials Chemistry A, vol. 3, no. 24, pp. 12626-12630, 2015.

[21] I. Sotiri, J. C. Overton, A. Waterhouse, and C. Howell, "Immobilized liquid layers: a new approach to anti-adhesion surfaces for medical applications," Experimental Biology and Medicine, vol. 241, no. 9, pp. 909-918, 2016.

[22] K. Golberg, N. Emuna, T. P. Vinod et al., "Anti-biofilms: novel anti-adhesive biomaterial patches: preventing biofilm with metal complex films (MCF) derived from a microalgal polysaccharide," Advanced Materials Interfaces, vol. 3, no. 9, 2016.

[23] J. Min, S. Baek, P. Somasundaran, and J. W. Lee, "Anti-adhesive behaviors between solid hydrate and liquid aqueous phase induced by hydrophobic silica nanoparticles," Langmuir, vol. 32, no. 37, pp. 9513-9522, 2016.

[24] J. K. Jo, A. El-Fiqi, J. H. Lee, D. A. Kim, H. W. Kim, and H. H. Lee, "Rechargeable microbial anti-adhesive polymethyl methacrylate incorporating silver sulfadiazine-loaded mesoporous silica nanocarriers," Dental Materials, vol. 33, no. 10, pp. e361-e372, 2017.

[25] M. R. Kalaee, M. H. N. Famili, and H. Mahdavi, "Cure kinetic of poly (alkyltetrasulfide) using a rheological method," Polymer-Plastics Technology and Engineering, vol. 48, no. 6, pp. 627-632, 2009.

[26] L. Núñez, J. Taboada, F. Fraga, and M. R. Núñez, "Kinetic study and time-temperature-transformation cure diagram for an epoxy-diamine system," Journal of Applied Polymer Science, vol. 66, no. 7, p. 1377, 1997. 


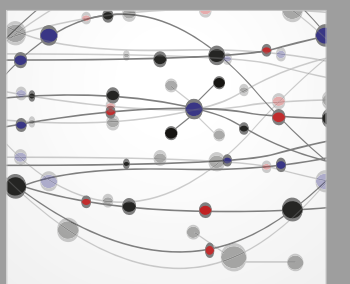

The Scientific World Journal
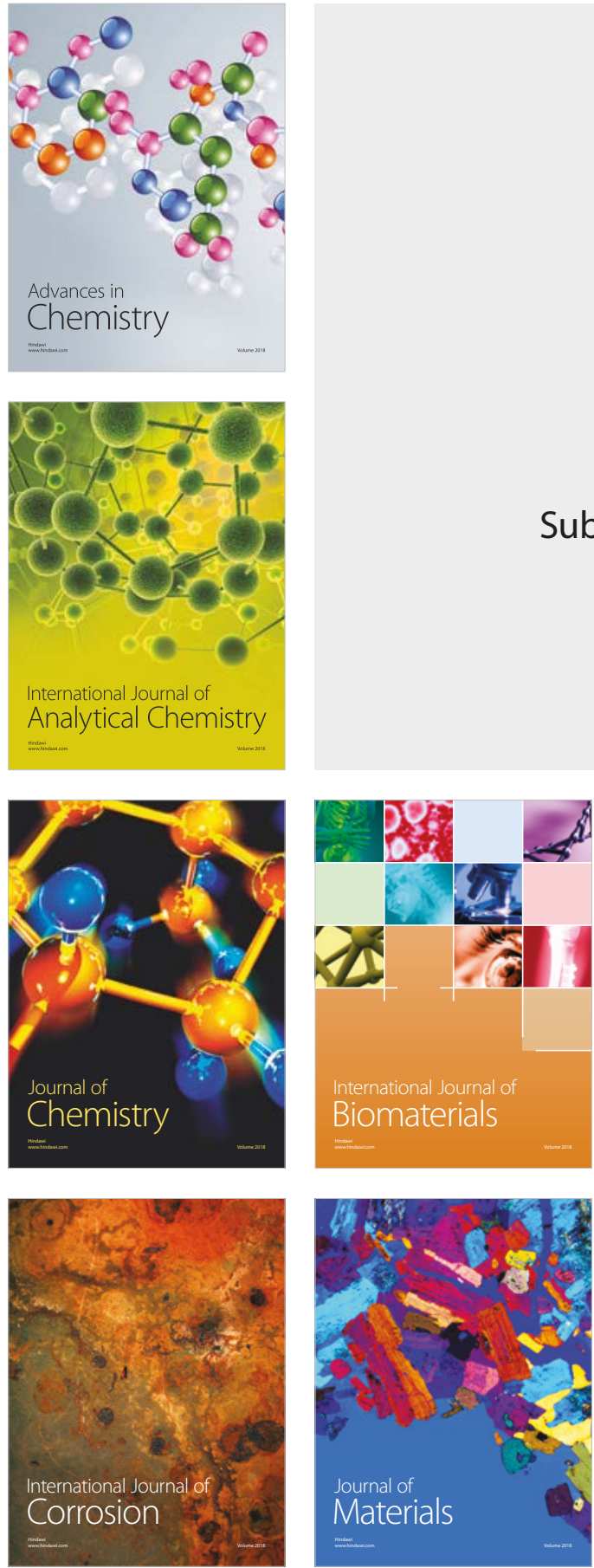

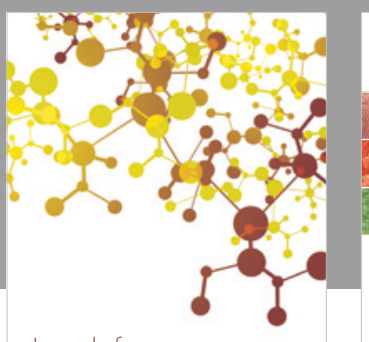

Journal of

Applied Chemistry
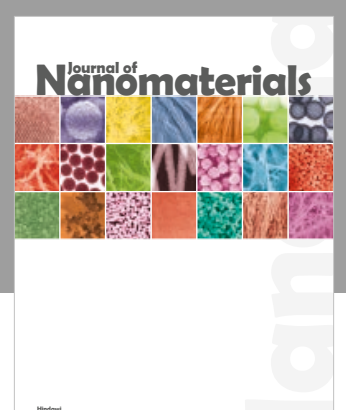

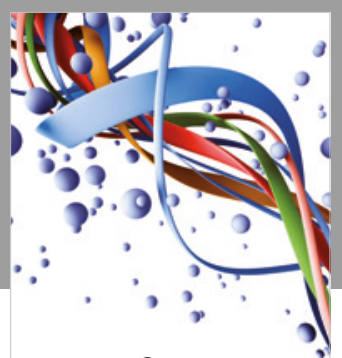

Scientifica

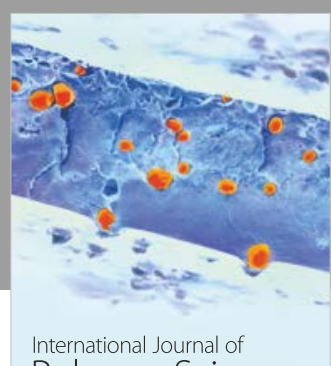

Polymer Science

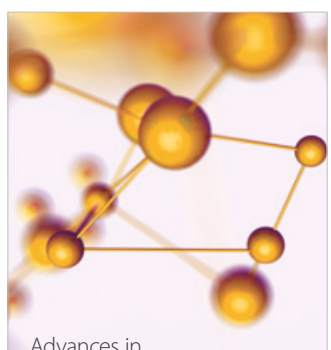

Physical Chemistry
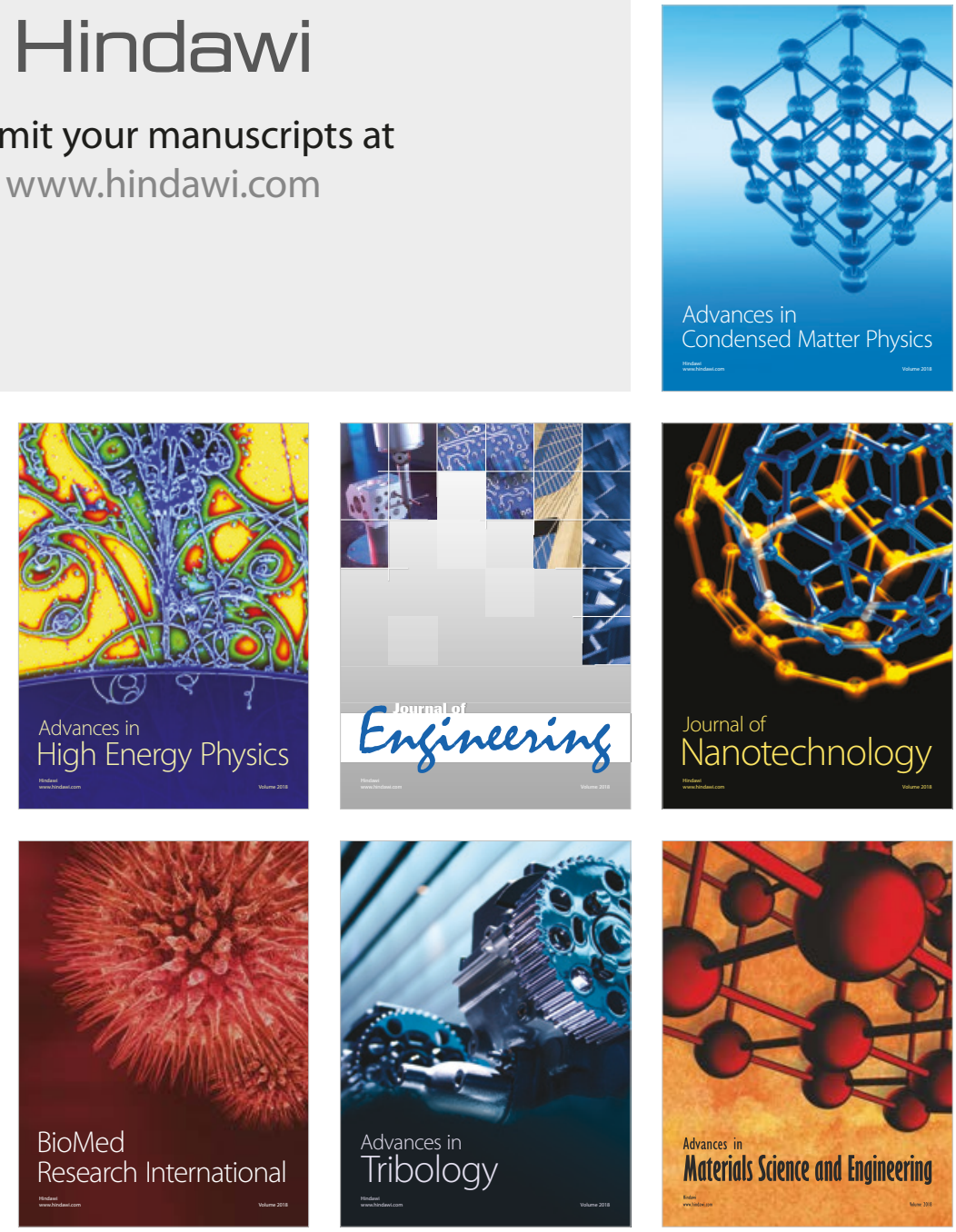